\title{
Femoral Neck Fracture Fixation Failure: A Review and Stepwise Approach
}

\author{
Seyed Mir Mansoor Moazen Jamshidi $\mathbb{D}^{1}$, Mohammadreza Razzaghof ${ }^{2}$, Seyed Mohammad Javad Mortazavi $\mathbb{1}^{3,}$ \\ ${ }^{1}$ Hip Fellowship, Department of Orthopedic Surgery, Joint Reconstruction Research Center, Imam Khomeini Hospital Complex, Tehran University of Medical Sciences, Tehran, Iran \\ ${ }^{2}$ Resident, Department of Orthopedic Surgery, Joint Reconstruction Research Center, Imam Khomeini Hospital Complex, Tehran University of Medical Sciences, Tehran, Iran \\ ${ }^{3}$ Professor, Department of Orthopedic Surgery, Joint Reconstruction Research Center, Imam Khomeini Hospital Complex, Tehran University of Medical Sciences, Tehran, Iran
}

Corresponding author: Seyed Mohammad Javad Mortazavi; Department of Orthopedic Surgery, Joint Reconstruction Research Center, Imam Khomeini Hospital Complex, Tehran University of Medical Sciences, Tehran, Iran. Tel: +98-9121776150, Email: smjmort@yahoo.com

Received: 05 April 2019; Revised: 20 July 2019; Accepted: 11 August 2019

Keywords:Femoral Neck Fractures; Hip Fracture; Orthopedic Fixation Devices; Revision Surgery; Bone Screws

Citation: Moazen Jamshidi SMM, Razzaghof M, Mortazavi SMJ. Femoral Neck Fracture Fixation Failure: A Review and Stepwise Approach. J Orthop Spine Trauma 2019; 5(3): 70-4.

\section{Background}

This study addresses the approach to the failure of a femoral neck fracture fixation construct and is performed with the aim to discuss the causes and treatment options of the failure of a femoral neck fixation construct in a stepwise approach (Figure 1).

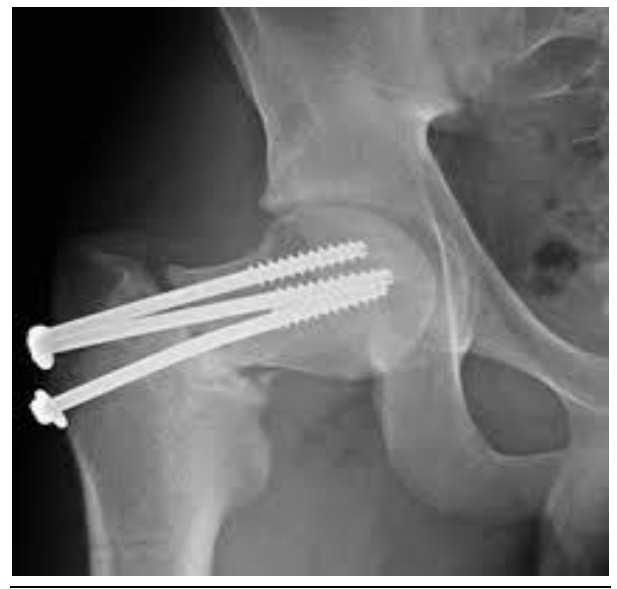

Figure 1. The Right hip anteroposterior (AP) radiograph of a 44year-old man with femoral neck fracture and right hip pain after six months of fixation in another center.

\section{Step 1: What Are the Types of Femoral Neck Fixation Failure?}

Femoral neck fractures represent challenging injuries to treat. It is because of the high-energy trauma mechanisms and the displaced fracture patterns typically found in these patients. Although there are controversies regarding the methods of reduction and internal fixation, an understanding of the fracture is required. In this section, the types of failure following femoral neck fracture fixation are discussed.

\section{1-Nonunion}

The followings are in favor of a femoral neck fracture nonunion:

- changes in fracture position by $10 \mathrm{~mm}$

- changes in the screw position by $5 \%$

- backing out of the screws

- perforation of the femoral head
- absence of bridging cortical bone in the fracture site after six to eight months

The incidence of nonunion following the fixation of femoral neck fracture varies between 10-30 percent based on the current literature $(1,2)$. The main causes of this complication are the damaged blood supply of the fractured femoral neck, wrong choice of the fixation implant, and incorrect reduction (3).

\section{2-Avascular Necrosis (AVN) of the Femoral Head}

There are five criteria for the diagnosis of femoral head AVN with high sensitivity and specificity:

a. The collapse of the femoral head without narrowing of the joint space or acetabular abnormality seen on radiography (including the crescent sign)

b. Demarcating sclerosis in the femoral head without narrowing of the joint space or acetabular abnormality seen on radiography

c. A cold-in-hot appearance on bone scan

d. A low-intensity band seen on T1-weighted MRI sequences (band pattern)

e. The evidence of trabecular and bone marrow necrosis on histological examination.

The sensitivity and specificity of the diagnosis using any combination of at least two of these criteria were found to be as high as $91 \%$ and $99 \%$, respectively (4-7).

Femoral head AVN following the fixation of femoral neck fracture has an incidence of 15-25 percent in most of the studies (8-10). Femoral head vascularity depends on the retinacular vasculature, especially the lateral epiphyseal artery, which contributes to 70 to $80 \%$ of the femoral head vascular supply $(11,12)$. The fracture causes vascular lesions, which is the main cause of necrosis. Other causes include the hematoma tamponade effect, reduced joint space, and increased pressure due to the lower extremity mal-positioning in extension, internal rotation, and abduction during the surgery. Head deformity does not occur due to direct cell death, but due to the repair process in the surrounding living bone and the subsequent pathologic fractures occurring at the boundary between the new and dead bones $(5,7)$.

\section{3-Reoperation}

As it is important to provide the optimal and anatomic reduction for osteosynthesis of femoral neck fractures in a single surgery (13), any reason leading to a reoperation and manipulation of the femoral neck vasculature might result in fixation failure (14). The incidence of reoperation 
following femoral neck fracture fixation was found to be about $18 \%$ (3). It could be due to complications such as nonunion, AVN, or implant failure $(14,15)$.

\section{4-Malunion, Implant Failure, and Infection}

Malunion, implant failure, and infection are less commonly reported causes of femoral neck fracture fixation failure. The incidence of reported femoral neck malunion was $7.1 \%$. The main criterion for malunion diagnosis would be the centrum-collum-diaphyseal (CCD) angle, that is, a different CCD angle of the injured side from the contralateral side means the fracture was united in malunion. The incidence of implant failure and surgical site infection in failed femoral neck fixations were 9.7\% and $5.1 \%$, respectively $(3,6,7)$.

\section{Step 2: Rule Out Infection}

To ruled out infection in a patient with nonunion, checking erythrocyte sedimentation rate (ESR), and Creactive protein (CRP) could be helpful to begin evaluation. If both measures are out of a normal range, i.e., ESR $>30$ and $C R P>10$, then the hip joint must be aspirated and the samples must be sent both for culture and synovial fluid analysis. If there is evidence of a septic nonunion (positive culture, synovial white blood cells $>$ 3000 per $\mu \mathrm{L}$, and synovial polymorphonuclear cells $>80 \%$ ), the first step would be the extraction of implant, administration of appropriate antibiotics based on the culture antibiogram, and waiting for the resolution of the infection. After the infection was resolved, the internal fixation should be performed (16).

\section{Step 3: Checking the Quality of the Reduction Technique}

Assessing the quality of reduction is very important before the femoral neck fracture fixation. It should be checked on anteroposterior (AP) and lateral radiographs based on the displacement and angulation of the fracture without adjustment for hip rotation. Based on these criteria, the quality of reduction could be categorized in three groups:

- Good: displacement $\leq 2 \mathrm{~mm}, \mathrm{AP}$ Garden angle (Figure 2) $160^{\circ}-175^{\circ}$, posterior or anterior angulation $\leq 0^{\circ}$

- Fair: displacement between 2 and $5 \mathrm{~mm}$, AP Garden angle $160^{\circ}-175^{\circ}$, posterior or anterior angulation between $10^{\circ}$ and $20^{\circ}$

- Bad: displacement $>5 \mathrm{~mm}$, AP Garden angle out of $160^{\circ}-175^{\circ}$, posterior or anterior angulation $>20^{\circ}(17)$.

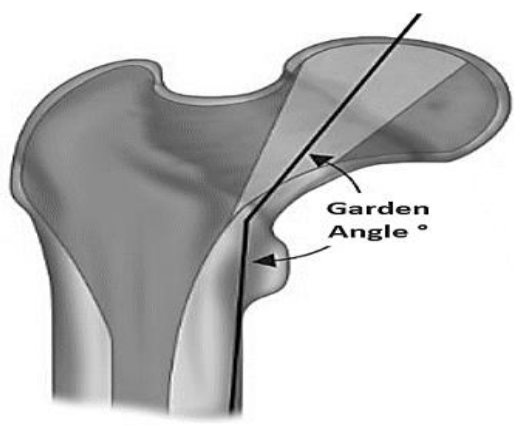

Figure 2. Garden angle defined in the true anteroposterior (AP) radiograph of the hip as the angle formed between the central axis of the medial trabecular system of femoral head and the medial cortex of the femoral shaft

It is established that varus mal-reduction or displacement causing non-anatomic reduction (positive or negative effect) is associated with fixation failure. If the quality of reduction is acceptable (good), there is no need to manipulate it for revision, but if the reduction is not acceptable (fair or bad), open or closed manipulation is mandatory to achieve optimum reduction (18).

Step 4: Does Femoral Neck Fracture Require an Open or Closed Reduction?

Several studies have reported favorable results following anatomical reduction of a femoral neck fracture (13). Few studies have shown that the type of fixation has a greater influence on the rate of complications (19). However, to the best of our knowledge, no reports have indicated the effectiveness of the reduction method on the outcome. In actual practice, deciding whether to use a closed or open reduction internal fixation (CRIF vs. ORIF) is a challenging decision to make. The surgeon should consider when adequate reduction is achieved with repeated manipulation. Furthermore, fluoroscopic projections cannot provide an accurate assessment of the quality of reduction. Overall, when an anatomic reduction cannot be achieved or the quality of reduction is in question, ORIF should be performed (20).

Step 5: Is the Femoral Head Viable?

According to the mentioned criteria, if there is a femoral head AVN, it should be treated based on the Ficat and Arlet classification of femoral head AVN. Treatment options vary from core decompression to total hip arthroplasty (THA). If there is no sign of $\mathrm{AVN}$, the treatment would be revision fixation or valgus osteotomy in patients under 60 years and THA in patients over 60 years (21).

Step 6: When Should the Surgeon Perform Valgus Osteotomy?

Valgus osteotomy should be performed in a failed femoral neck fixation if all the below criteria are met:

- Pauwels type 3 fracture (high shearing force)

- Intact cartilage

- Viable head

- Sufficient quality and quantity of femoral head bone for purchase

- Sufficient femoral neck bone

Age $<60$ years $(22)$

The best method for valgus osteotomy is intertrochanteric osteotomy, with the correction of the fracture verticality angle to $25^{\circ}$ (23). It is important to know that it is not imperative to correct all the cases to a $25^{\circ}$-angle, and some smaller degrees of correction with a higher-than$25^{\circ}$ verticality is also acceptable (24). It is established that valgus osteotomy does not change future arthroplasty results (25). Valgus osteotomy should be performed with a $90^{\circ}$ double-angle blade with appropriate templating (26).

The following example (Figure 3 ) is for a 33-year-old female patient suffering from hip pain after the fixation of a femoral neck fracture who came to our clinic. Due to the viability of the femoral head, Pauwels angle of $75^{\circ}$ (type 3 ), and good bone stock, we decided to perform valgus osteotomy. Step 6: When should the surgeon do re-osteosynthesis?

In a failed femoral neck fracture, if all the below criteria are met, re-osteosynthesis would be recommended:

- No indication for valgus osteotomy

- Viable head

- Sufficient bone in head and neck

- Age $<60$ years 


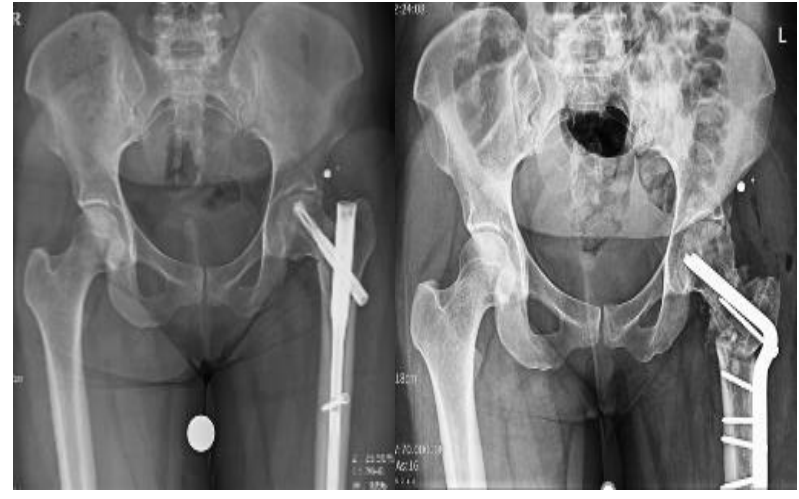

Figure 3. A 33-year-old female patient with left hip pain after eight months following the fixation of a femoral neck fracture (left) who underwent valgus osteotomy (right)

As can be seen in figure 4, our 45-year-old male patient with failed ORIF of the femoral neck has been treated with re-osteosynthesis using a dynamic hip screw (DHS). It was because the fracture was with low shearing force, the femoral head was viable, and there was good bone stock.

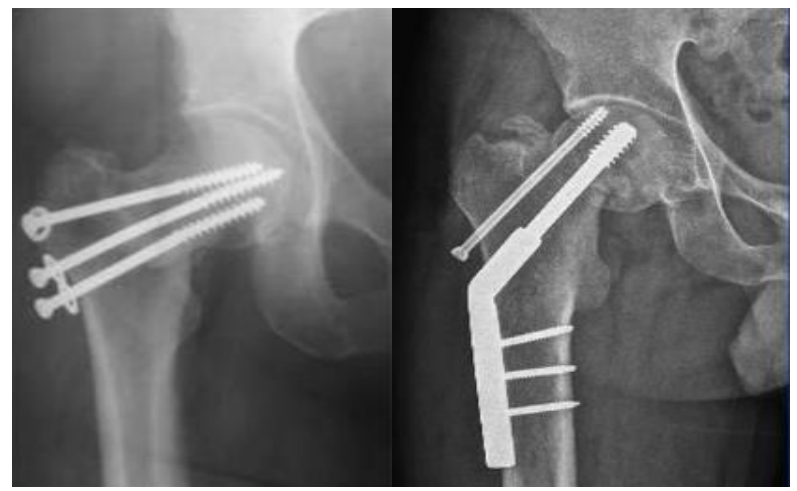

Figure 4. A 45-year-old male patient with failed open reduction internal fixation (ORIF) of the femoral neck (left) who underwent re-osteosynthesis using a dynamic hip screw (right)

\section{Step 7: What Is the Best Implant for Re-osteosynthesis?}

More than 100 different options are available for re-osteosynthesis of a femoral neck fracture (27). According to the study by Bhandari et al., $68 \%, 19 \%$, and $2 \%$ of orthopedic surgeons preferred respectively cannulated screws, DHS, and cephalomedullary nails for a femoral neck fracture (Garden type III) in patients under 60 years (28). There might be no preferences between the devices except in some issues, which are discussed below.

7-1. Cannulated Screw (CS): Cannulated screws were introduced in 1996. They maintain the fracture from varus and posterior migration. The advantage of this technique is the minimal soft tissue stripping and it is optimal for revision surgeries. The rates of nonunion and AVN have been reported to be $4 \%$ and $18 \%$ following the use of CS. The most important complications after CS are the subtrochanteric fracture and femoral neck shortening due to collapse (29).

\section{7-7-1. What Is the Best Configuration for Cannulated Screw} Placement in Femoral Neck Fracture?

The best configuration is an inverted triangle, as shown in figure 5 , that is, one screw placed in the inferiorcenter and two others in the anterior and posterior position proximally (30).

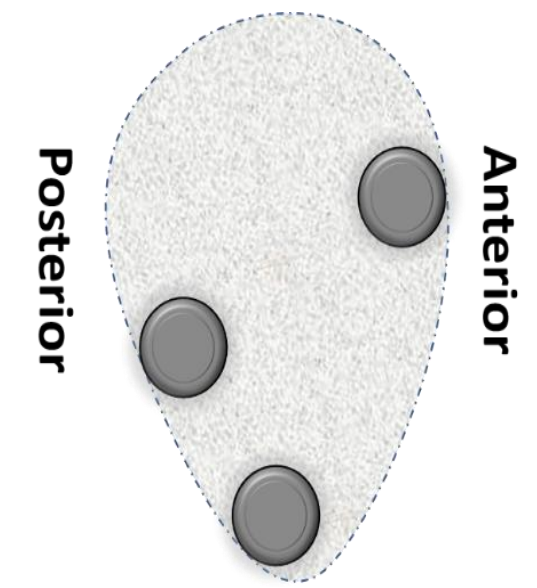

Figure 5. Schematic demonstration of the best proposed configuration of screws in the femoral neck (sagittal view)

\section{7-7-2. What Is the Best Order for Screw Placement in Femoral Neck Fractures?}

The screws are best to be placed in this order: first, the inferior, then anterior, and at last the posterior screw. If there is comminution in the posterior segment, we place the anterior screw first, then the posterior, and at last the inferior screw (31).

\section{7-7-3. How Many Screws Are Needed for Orif of Femoral Neck Fracture?}

Three screws are sufficient for ORIF of the femoral neck fracture. If there is posterior comminution, four screws would be better. Placing the screws in a non-parallel configuration might have a better outcome (31).

\section{7-7-4. Is it Necessary to Use Washer(s) in the Fixation of} Femoral Neck Fracture by CS?

Washers increase the insertion torque during surgery, and they are very helpful for applying compression in the fracture site (32).

\section{7-7-5. What Are the Properties of the CS Used in the Fixation of Femoral Neck Fracture?}

The $7.3 \mathrm{~mm}$ cannulated partial threaded titanium screws are sufficient. In case of severe comminution at the fracture site, fully threaded screws should be used for fracture fixation. Screw threads should pass the fracture site to be capable of applying compression; however, if there is comminution, that would not be required (32).

7-2. DHS: It could be used in all types of femoral neck fractures, especially in basicervical, Pauwels type 3 , and osteoporotic fractures. It is better to be always combined with an anti-rotational screw for better results, as it precludes rotation at the fracture site. The disadvantages of DHS are as follows: 1) risk of AVN, especially when inserted in the superoposterior quadrant of the femoral neck, 2) need for more dissection, and 3) a harder revision (33).

7-3. Cephalomedullary Nail (PFNA): It is used in bascicervical fractures and has equal efficacy to DHS. It is preferable to be used with two screws. A short type of nail is usually sufficient unless the patient's bone quality is poor. In a large meta-analysis, no difference was found among CS, DHS, and PFNA, and the choice of the implant was according to the surgeon's preference (34).

In the failure of femoral neck fracture fixation, accurate and rapid treatment is necessary based on the viability (AVN) of the femoral head, adequacy of bone stock, and fracture verticality. If there is a femoral head $A V N$, the treatment varies according to Ficat classification from core decompression to THA. Otherwise, the 
treatment includes valgus osteotomy (high verticality) and re-osteosynthesis (low verticality) for patients under 60 years, and THA for those above 60 years.

\section{Conflict of Interest}

The authors declare no conflict of interest in this study.

\section{Acknowledgments}

None.

\section{References}

1. Lu-Yao GL, Keller RB, Littenberg B, Wennberg JE. Outcomes after displaced fractures of the femoral neck. A meta-analysis of one hundred and six published reports. Orthopedic Trauma Directions. 1994;3(3):29-33.

2. Davidovitch RI, Jordan CJ, Egol KA, Vrahas MS. Challenges in the treatment of femoral neck fractures in the nonelderly adult. I Trauma. 2010;68(1):236-42. doi: 10.1097/TA.0b013e3181c428ce. [PubMed: 20065780].

3. Slobogean GP, Sprague SA, Scott T, Bhandari M. Complications following young femoral neck fractures. Injury. 2015;46(3):48491. doi: 10.1016/j.injury.2014.10.010. [PubMed: 25480307].

4. Sugano N, Kubo T, Takaoka K, Ohzono K, Hotokebuchi T, Matsumoto T, et al. Diagnostic criteria for non-traumatic osteonecrosis of the femoral head. A multicentre study. J Bone Joint Surg Br. 1999;81(4):590-5. doi: 10.1302/0301-620x.81b4.9393. [PubMed: 10463726].

5. Ehlinger M, Moser T, Adam P, Bierry G, Gangi A, de Mathelin M, et al. Early prediction of femoral head avascular necrosis following neck fracture. Orthop Traumatol Surg Res. 2011;97(1):79-88. doi: 10.1016/j.otsr.2010.06.014. [PubMed: 21087905].

6. Estrada LS, Volgas DA, Stannard JP, Alonso JE. Fixation failure in femoral neck fractures. Clin Orthop Relat Res. 2002;(399):110-8. doi: 10.1097/00003086-200206000-00013. [PubMed: 12011699].

7. Bachiller FG, Caballer AP, Portal LF. Avascular necrosis of the femoral head after femoral neck fracture. Clin Orthop Relat Res. 2002;(399):87-109. doi: 10.1097/00003086-20020600000012. [PubMed: 12011698].

8. Nikolopoulos KE, Papadakis SA, Kateros KT, Themistocleous GS, Vlamis JA, Papagelopoulos PJ, et al. Long-term outcome of patients with avascular necrosis, after internal fixation of femoral neck fractures. Injury. 2003;34(7):525-8. doi: 10.1016/s0020-1383(02)00367-4. [PubMed: 12832180].

9. Asnis SE, Wanek-Sgaglione L. Intracapsular fractures of the femoral neck. Results of cannulated screw fixation. J Bone Joint Surg Am. 1994;76(12):1793-803. doi: 10.2106/00004623199412000-00005. [PubMed: 7989384].

10. Lu-Yao GL, Keller RB, Littenberg B, Wennberg JE. Outcomes after displaced fractures of the femoral neck. A meta-analysis of one hundred and six published reports. J Bone Joint Surg Am. 1994;76(1):15-25. doi: 10.2106/00004623-199401000-00003. [PubMed: 8288658].

11. Sevitt S, Thompson RG. The distribution and anastomoses of arteries supplying the head and neck of the femur. $J$ Bone Joint Surg Br. 1965;47:560-73. [PubMed: 14341080].

12. Trueta J, Harrison $\mathrm{MH}$. The normal vascular anatomy of the femoral head in adult man. I Bone Joint Surg Br. 1953;35B(3):442-61. [PubMed: 13084696].

13. Yang JI, Lin LC, Chao KH, Chuang SY, Wu CC, Yeh TT, et al. Risk factors for nonunion in patients with intracapsular femoral neck fractures treated with three cannulated screws placed in either a triangle or an inverted triangle configuration. J Bone
Joint Surg Am. 2013;95(1):61-9. doi: 10.2106/JB]S.K.01081 [PubMed: 23283374].

14. Stockton DJ, O'Hara LM, O'Hara NN, Lefaivre KA, O'Brien PJ, Slobogean GP. High rate of reoperation and conversion to total hip arthroplasty after internal fixation of young femoral neck fractures: A population-based study of 796 patients. Acta Orthop. 2019;90(1):21-5. doi: 10.1080/17453674.2018.1558380. [PubMed: 30712497]. [PubMed Central: PMC6366467].

15. Gjertsen JE, Lie SA, Vinje T, Engesaeter LB, Hallan G, Matre K, et al. More re-operations after uncemented than cemented hemiarthroplasty used in the treatment of displaced fractures of the femoral neck: an observational study of 11,116 hemiarthroplasties from a national register. J Bone Joint Surg Br. 2012;94(8):1113-9. doi: 10.1302/0301-620X.94B8.29155. [PubMed: 22844055].

16. Liporace F, Gaines R, Collinge C, Haidukewych GJ. Results of internal fixation of Pauwels type-3 vertical femoral neck fractures. I Bone Joint Surg Am. 2008;90(8):1654-9. doi: 10.2106/JBJS.G.01353. [PubMed: 18676894].

17. Lindequist $\mathrm{S}$, Tornkvist $\mathrm{H}$. Quality of reduction and cortical screw support in femoral neck fractures. An analysis of 72 fractures with a new computerized measuring method. $J$ Orthop Trauma. 1995;9(3):215-21. doi: 10.1097/00005131199506000-00006. [PubMed: 7623173].

18. Garden RS. Low-angle fixation in fractures of the femoral neck J Bone Joint Surg. 1961;43(4):647-63.

19. Wang W, Wei J, Xu Z, Zhuo W, Zhang Y, Rong H, et al. Open reduction and closed reduction internal fixation in treatment of femoral neck fractures: A meta-analysis. BMC Musculoskelet Disord. 2014;15:167. doi: 10.1186/1471-2474-15-167. [PubMed: 24885566]. [PubMed Central: PMC4047776].

20. Song KS. Displaced fracture of the femoral neck in children: Open versus closed reduction. I Bone Joint Surg $B r$ 2010;92(8):1148-51. doi: 10.1302/0301-620X.92B8.24482. [PubMed: 20675763].

21. Moon ES, Mehlman CT. Risk factors for avascular necrosis after femoral neck fractures in children: 25 Cincinnati cases and meta-analysis of 360 cases. J Orthop Trauma. 2006;20(5):323-9. doi: 10.1097/00005131-200605000-00005. [PubMed:16766935].

22. Schoenfeld AJ, Vrabec GA. Valgus osteotomy of the proximal femur with sliding hip screw for the treatment of femoral neck nonunions: The technique, a case series, and literature review. I Orthop Trauma. 2006;20(7):485-91. doi: 10.1097/00005131-200608000-00006. [PubMed:16891940].

23. Müller ME. Intertrochanteric osteotomy: indication, preoperative planning, technique. In: Schatzker J, Aronson J, Bombelli R, Editors. The intertrochanteric osteotomy. Berlin, Germany: Springer; 1984. p. 25-66.

24. Yuan BJ, Shearer DW, Barei DP, Nork SE. Intertrochanteric osteotomy for femoral neck nonunion: Does "undercorrection" result in an acceptable rate of femoral neck union? J Orthop Trauma. 2017;31(8):420-6. doi: 10.1097/BOT.0000000000000869. [PubMed: 28430719].

25. Min BW, Bae KC, Kang CH, Song KS, Kim SY, Won YY. Valgus intertrochanteric osteotomy for non-union of femoral neck fracture. Injury. 2006;37(8):786-90. doi:10.1016/j.injury.2006.02.045. [PubMed:16765958].

26. Chotigavanichaya C, Leeprakobboon D, Eamsobhana P, Kaewpornsawan K. Results of surgical treatment of coxa vara in children: Valgus osteotomy with angle blade plate fixation. J Med Assoc Thai. 2014;97(Suppl 9):S78-S82. [PubMed: 25365895].

27. Parker MJ, Blundell C. Choice of implant for internal fixation of femoral neck fractures. Meta-analysis of 25 randomised trials including 4,925 patients. Acta Orthop Scand. 1998;69(2):138-43. doi: 10.3109/17453679809117614. [PubMed: 9602770]. 
28. Bhandari M, Tornetta $\mathrm{P} 3^{\text {rd }}$, Hanson B, Swiontkowski MF. Optimal internal fixation for femoral neck fractures: Multiple screws or sliding hip screws? JOrthop Trauma. 2009;23(6):4037. doi: 10.1097/BOT.ob013e318176191f. [PubMed: 19550225].

29. Booth KC, Donaldson TK, Dai QG. Femoral neck fracture fixation: A biomechanical study of two cannulated screw placement techniques. Orthopedics. 1998;21(11):1173-6. [PubMed: 9845448].

30. Oakey JW, Stover MD, Summers HD, Sartori M, Havey RM, Patwardhan AG. Does screw configuration affect subtrochanteric fracture after femoral neck fixation? Clin Orthop Relat Res. 2006;443:302-6. doi: 10.1097/01.blo.0000188557.65387.fc. [PubMed: 16462455].

31. Zlowodzki M, Jonsson A, Paulke R, Kregor PJ, Bhandari M. Shortening after femoral neck fracture fixation: Is there a solution? Clin Orthop Relat Res. 2007;461:213-8. doi: 10.1097/BLO.ob013e31805b7ec4. [PubMed: 17415006].

32. Zlowodzki M, Weening B, Petrisor B, Bhandari M. The value of washers in cannulated screw fixation of femoral neck fractures. J Trauma. 2005;59(4):969-75. doi: 10.1097/01.ta.0000188130.99626.8c. [PubMed:16374290].

33. Siavashi B, Aalirezaei A, Moosavi M, Golbakhsh MR, Savadkoohi D, Zehtab MJ. A comparative study between multiple cannulated screws and dynamic hip screw for fixation of femoral neck fracture in adults. Int Orthop. 2015;39(10):206971. doi: 10.1007/s00264-015-2881-9. [PubMed: 26152248].

34. Carey TP, Galpin RD. Flexible intramedullary nail fixation of pediatric femoral fractures. Clin Orthop Relat Res. 1996;(332):110-8. doi: 10.1097/00003086-199611000-00015. [PubMed: 8913152]. 